\title{
XIX \\ AVALIAÇÃO DA QUALIDADE BACTERIOLÓGICA E ESPÉCIES NITROGENADAS DAS ÁGUAS SUBTERRÂNEAS DE POÇOS DA ÁREA URBANA DE BARREIRAS-BA
}

\author{
Luiz Fernando Souza Almeida ${ }^{1 *}$; Oldair Donizeti Leite ${ }^{2}$; Leandro da Cruz da Guarda ${ }^{3}$
}

\begin{abstract}
Resumo - O presente trabalho avaliou a qualidade das águas subterrâneas na área urbana do município de Barreiras-BA, através de dois métodos de exames bacteriológicos (tubos múltiplos e colitag), para comparações de resultados e espécies nitrogenadas, que são parâmetros que indicam contaminação por esgotos (amônio, nitrito e nitrato). As coletas foram realizadas em 20 poços, distribuídos em rasos e profundos, com quatro campanhas para os exames bacteriológicos e duas para as espécies nitrogenadas, em época de chuvas e de estiagem. Dos resultados bacteriológicos, de 80 amostras analisadas, $65 \%$ apresentaram-se insatisfatórios, que pode estar relacionado ao aspecto construtivo, localização do poço e variações sazonais, e com resultados dos dois métodos muito semelhantes. Nas espécies nitrogenadas, somente nos poços rasos, o íon amônio ultrapassou o Valor Máximo Permissível $\left(1,5 \mathrm{mg} \mathrm{L}^{-1} \mathrm{~N}-\mathrm{NH}_{4}+\right)$. O nitrito encontrou-se dentro dos padrões nos poços rasos e profundos. Quanto ao nitrato, nos poços rasos, $83 \%$ ultrapassaram o VMP $\left(10 \mathrm{mg} \mathrm{L}^{-1}\right.$ ${\mathrm{N}-\mathrm{NO}_{3}}^{-}$) e os profundos, com valores variando de 4,0 a $14,43 \mathrm{mg} \mathrm{L}^{-1} \mathrm{~N}_{-} \mathrm{NO}_{3}{ }^{-}$, que são valores de alerta. A maior parte desses poços se encontra na área urbana de ocupação mais antiga da cidade.
\end{abstract}

Palavras-Chave: Águas subterrâneas, grupo coliforme, espécies nitrogenadas.

\section{ASSESSMENT OF BACTERIOLOGICAL QUALITY AND NITROGEN SPECIES OF GROUNDWATER OF WELLS IN THE URBAN AREA OF BARREIRAS-BA}

\begin{abstract}
This present study evaluated the quality of groundwater in the urban area of the municipality of Barreiras-BA through two methods of bacteriological tests (multiple tubes and Colitag), and nitrogen species, which are parameters that indicate contamination wastewater (ammonium, nitrite and nitrate). Samples were collected in 20 wells, distributed in shallow and deep, with four campaigns for bacteriological tests and two for the nitrogen series in the rainy season and summer. Bacteriological results of 80 samples analyzed, $65 \%$ exhibited unsatisfactory, which may be related to the constructive aspect, bad location, seasonal variations and results of two similars related methods. In nitrogen species, only in shallow wells, the ammonium ion exceeded the Maximum Permissible $\left(1.5 \mathrm{mg} \mathrm{L}^{-1} \mathrm{~N}_{-} \mathrm{NH}_{4}{ }^{+}\right)$, in the deep, were within the standards. Nitrite, both in shallow wells as in the deep, attended Governing Law and how much nitrate in shallow wells, $83 \%$ exceeded the VMP $\left(10 \mathrm{mg} \mathrm{L}^{-1} \mathrm{~N}^{-N_{3}}{ }^{-}\right)$and deep, with values ranging from 4,0 to $14,43 \mathrm{mg} \mathrm{L}^{-}$ ${ }^{1} \mathrm{~N}_{-} \mathrm{NO}_{3}$, which are warning values. The most of these wells is in the urban area of more ancient occupation of the city.
\end{abstract}

Keywords: Groundwater, coliform group, nitrogen species.

\footnotetext{
${ }^{1}$ Universidade Federal do Oeste da Bahia/UFOB; Programa de Pós-Graduação em Ciências Ambientais; fone: (77) 99191-6499; e-mail: luizfernando@ifba.edu.br

2 Universidade Federal do Oeste da Bahia/UFOB; Programa de Pós-Graduação em Ciências Ambientais; fone: (77) 98848-7073; e-mail: oldair.leite@gmail.com

3 Universidade Federal do Oeste da Bahia/UFOB; Programa de Pós-Graduação em Ciências Ambientais; fone: (77) 98157-7452; e-mail: leandro.guarda.47@gmail.com

*Autor Correspondente
} 


\section{1 - INTRODUÇÃO}

No Brasil houve um grande crescimento pela procura de águas subterrâneas, o que fez aumentar a construção de poços que, na maioria das vezes, não obedecem às normas técnicas e já é fato de preocupação mundial (Medeiros et al., 2009) e podem ter como origem o não isolamento de rochas superficiais alteradas na perfuração; ausência de laje de proteção sanitária e altura inadequada da boca do poço; proximidade com pontos contaminados, entre outras aspectos, visto que, essa forma de construção dentro dos padrões exigidos é de fundamental importância para garantir a qualidade da água captada, bem como sua operação (Conejo et al., 2007).

A maior parte da água subterrânea se origina a partir do excesso de chuva que se infiltra (diretamente ou indiretamente) na superfície do solo. Como consequência, as atividades que se desenvolvem na superfície podem ameaçar a qualidade dessas águas (Foster et al., 2006), através do destino final do esgoto doméstico e industrial em fossas e tanques sépticos, a disposição inadequada de resíduos sólidos urbanos e industriais, postos de combustíveis e lavagem e a modernização da agricultura que representam fontes de contaminação dessas águas por bactérias, vírus patogênicos, parasitas, substâncias inorgânicas e orgânicas ( Silva e Araújo, 2003).

A identificação de micro-organismos patógenos na água é possível, porém é uma prática difícil, buscando-se a realização de exames de micro-organismos indicadores de contaminação fecal, que são as bactérias do grupo coliforme, que estão presentes no intestino do homem e de animais de sangue quente, tendo também nesse grupo, bactérias de origem não exclusivamente fecal. A Escherichia coli pertence também ao grupo coliforme e representa $95 \%$ dessas bactérias, sendo considerada a melhor indicadora desse tipo de contaminação (Marquezi et al., 2010).

Quanto às espécies nitrogenadas, o composto menos oxidado como a amônia $\left(\mathrm{NH}_{3}\right)$, pode se encontrar em águas superficiais ou subterrâneas, apresentando geralmente baixas concentrações, devido ocorrer uma fácil adsorção por partículas do solo ou à sua oxidação a nitrito e nitrato, porém em concentrações elevadas, pode estar próximo ao foco de poluição, por ser estável no sistema redutor (Alaburda e Nishiara, 1998), À medida em que se afasta da fonte poluidora, ocorrerá uma 
diminuição na concentração dessa espécie e aumento gradativo do nitrato, pelo contato com águas mais ricas em oxigênio (Varnier e Hirata, 2002).

De acordo com Cabral (2007), a avaliação da ocorrência das espécies nitrogenadas nas águas de abastecimento é de grande importância, devido aos riscos que essas substâncias oferecem à saúde humana, como o nitrato, em que índices superiores a $10 \mathrm{mg} \mathrm{L}^{-1} \mathrm{NO}_{3}{ }^{-}-\mathrm{N}\left(45 \mathrm{mg} \mathrm{L}^{-1} \mathrm{NO}_{3}{ }^{-}\right)$, pode ocasionar doenças como a metahemoglobinemia ou "síndrome do bebê azul" (menores de seis meses de idade), quadro de cianose, além de causar câncer estomacal ou de esôfago pela formação de N-nitrosaminas.

A rede coletora de esgoto existente atualmente em Barreiras foi projetada e implantada em épocas diferentes, atendendo somente alguns bairros da cidade e não houve um projeto que atendesse toda área urbana do município. Dessa forma, as ligações de esgoto corresponde a um atendimento de cerca de $10 \%$, que é um valor muito baixo, devido ao porte e importância da cidade no cenário socioeconômico do estado. Salienta-se que o município se encontra em fase de implantação do novo sistema de esgotamento sanitário em nível mais amplo (BARREIRAS, 2010).

\section{2 - OBJETIVOS}

Levando-se em consideração a importância dos aspectos demonstrados, o objetivo desse trabalho foi avaliar a qualidade bacteriológica e das espécies nitrogenadas das águas subterrâneas na área urbana de Barreiras-BA.

\section{1 - Objetivos Específicos}

Conhecer a qualidade das água subterrânea distribuída em 20 poços do perímetro urbano através de exames bacteriológicos e espécies nitrogenadas;

Determinar a presença e estimativa do Número Mais Provável (NMP) de micro-organismos patógenos, especificamente coliformes totais e coliformes termotolerantes pela técnica dos tubos múltiplos; 
Avaliar a eficiência do método cromogênico/fluorogênico (colitag), utilizado para contagens de coliformes totais e Escherichia coli, determinando comparações com os resultados da técnica dos tubos múltiplos;

Obter um perfil dos índices de contaminações das águas de poços subterrâneos em áreas urbanas, com base na Legislação Brasileira de Águas Subterrânea do Conselho Nacional do Meio Ambiente (CONAMA) e pela Portaria do Ministério da Saúde (MS).

\section{3 - MATERIAL E MÉTODOS}

\section{1 - Área de Estudo}

O presente estudo foi desenvolvido no perímetro urbano do município de Barreiras-BA, localizado na mesorregião oeste do Estado da Bahia, entre as coordenadas geográficas 1206'992"' de Latitude Sul e $044^{\circ} 57^{\prime} 805^{\prime}$ " de Longitude Oeste (Figura 1) e está inserida na bacia hidrográfica do Rio Grande, afluente da margem esquerda do Rio São Francisco (BARREIRAS, 2010).
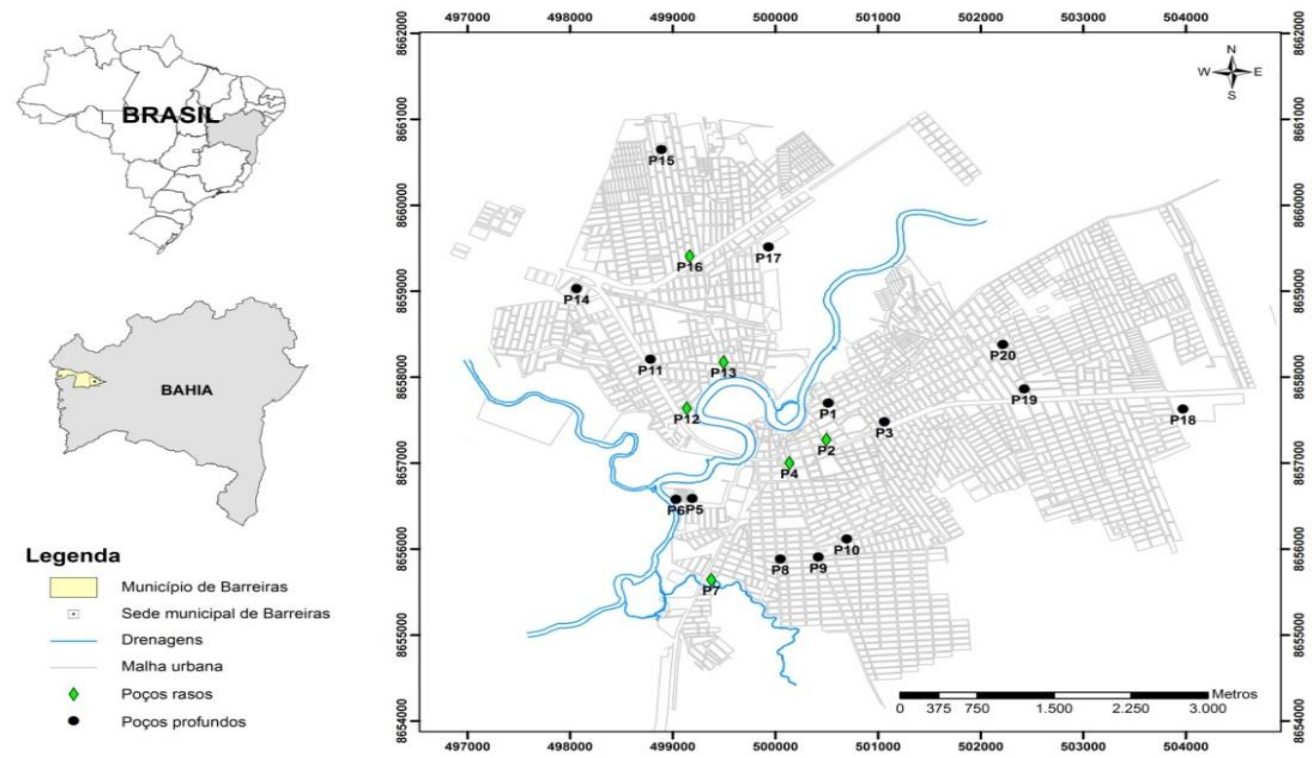

Figura 1: Área urbana de Barreiras/BA, com localização de poços amostrados (Fonte: Adaptada de Rocha, 2013). 
O município de Barreiras é considerado um importante entroncamento rodoviário entre o Norte, o Nordeste e o Centro-Oeste do país, com área geográfica de $7.895 \mathrm{~km}^{2}$ e com população estimada em 137.832 habitantes (IBGE, 2010), sendo atualmente o município mais populoso do Oeste da Bahia, devido influência do processo de modernização agrícola vinculado à produção de grãos. Apesar do desenvolvimento econômico, a rede de esgoto atende somente cerca de $10 \%$ da população urbana, o que compromete as águas subterrâneas (BARREIRAS, 2010).

O cerrado é considerado a maior região fitoecológica do município, com precipitação média entre 900 a $1.500 \mathrm{~mm} / \mathrm{ano}$, com média na sede municipal de $1.122 \mathrm{~mm}$. As chuvas ocorrem no período de outubro a abril, correspondendo a $94 \%$ do total precipitado no ano. Os meses de maio a setembro apresentam-se praticamente secos, que corresponde a cerca de $10 \%$ do total precipitado no ano, com altimetria variando de 450 a $500 \mathrm{~m}$ na parte central, ocupada pelo vale do Rio Grande e cotas dos divisores de água entre 700 a 1000 m (BARREIRAS, 2010).

Referente à geologia regional, a área de estudo se encontra sob o domínio das rochas metassedimentares do Proterozóico Superior, em que se inclui o Grupo Bambuí, que constitui uma das unidades da bacia do São Francisco, representado pelas formações São Desidério, Serra da Mamona e Riachão das Neves (Egídyo Silva, 1987) e no contexto local, são constatadas litologias referentes à Formação Riachão das Neves ao longo principalmente das vertentes da Serra do Mimo e da Bandeira representada por rochas metapelíticas, que recobre o Aquífero Cárstico Fissural, o qual constitui o mais expressivo ambiente hidrogeológico local (BARREIRAS, 2010).

\section{2 - Coletas e preservação de amostras}

Foram realizadas amostragens de 20 poços do perímetro urbano de Barreiras-BA (Figura 1), distribuídos em 6 poços rasos (menor que 20 metros de profundidade) e 14 profundos (maior que 40 metros de profundidade), em quatro campanhas para exames bacteriológicos e duas campanhas para as análises dos compostos nitrogenados (amônio, nitrito e nitrato), entre janeiro de 2014, época de chuvas e julho de 2014 em período de estiagem. Os procedimentos de coleta e preservação foram de acordo com (Santos, 2008) e os poços foram selecionados de acordo trabalhos de cadastramentos realizados por (Rocha, 2013) 


\section{3 - Metodologia analítica e estudo dos resultados}

Os exames bacteriológicos e as análises dos compostos nitrogenados foram de acordo com a metodologia descrita pela American Public Health Association (APHA, 2005). Os parâmetros bacteriológicos foram: coliformes totais e coliformes termotolerantes, pela metodologia dos tubos múltiplos, NMP - Número Mais Provável/100 mL e o método rápido (substrato definido colitag cromogênico/fluorogênico) e leituras através da tabela do NMP/100 mL. Quanto aos compostos nitrogenados: amônio pelo método (Espectrofotométrico Berthelot); nitrito (Espectrofotométrico Griess) e nitrato (Espectrofotométrico - Fluxo Redução Cádmio e Griess).

Para estudo dos resultados buscou-se a Portaria do Ministério da Saúde no 2.914/11 (BRASIL, 2011), que referencia o grau de potabilidade da água e a Resolução do Conselho Nacional do Meio Ambiente, CONAMA no 396/08 (BRASIL/2008), que enquadra as águas subterrâneas. Para nitrato, o Valor Máximo Permissível é de $10 \mathrm{mg}$ de nitrogênio de nitrato $\left(\mathrm{N}-\mathrm{NO}_{3}{ }^{-}\right.$) por litro; nitrito, com VMP de 1,0 mg de nitrogênio de nitrito $\left(\mathrm{N}^{-\mathrm{NO}_{3}}{ }^{-}\right)$por litro; amônia, VMP de 1,5 mg de nitrogênio $\left(\mathrm{NH}_{3}\right)$ por litro Para os exames bacteriológicos: coliformes totais e termotolerantes e Escherichia coli, deverão dar ausência em $100 \mathrm{~mL}$ da amostra.

\section{4 - RESULTADOS E DISCUSSÕES}

Nas Figuras 2, 3, 4 e 5 são demostradas as porcentagens médias de comparações de resultados de coliformes totais, coliformes termotolerantes e Escherichia coli, ambas detectadas através de exames bacteriológicos, pelos métodos dos Tubos Múltiplos e Colitag em 6 poços rasos $(<20 \mathrm{~m})$ e 14 poços profundos (> $40 \mathrm{~m}$ ) realizados em quatro campanhas, sendo as duas primeiras, em período de chuvas (janeiro e fevereiro/2014) e duas em período de seca (junho e julho/2014). 


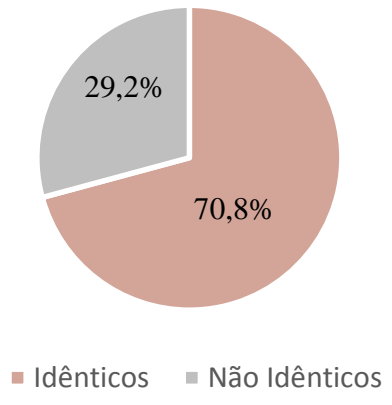

Figura 2: Comparação entre os métodos de tubos múltiplos e colitag para coliformes totais - poços rasos.

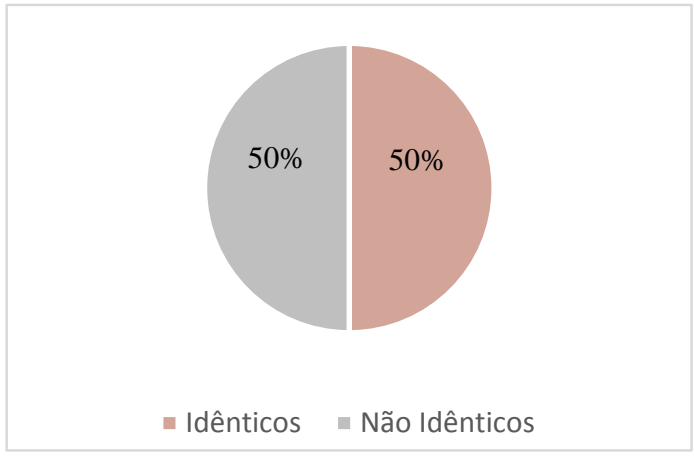

Figura 3: Comparação entre os métodos de tubos múltiplos e colitag para coliformes totais - poços profundos.

Através dos resultados dos exames para coliformes totais nos poços rasos, pelo método dos tubos múltiplos e colitag, conforme Figura 2, observou-se que 70,8\% apresentaram resultados idênticos e 29,2 \%, não idênticos, sendo que, dois, desses seis poços rasos, se destacaram: P7 e P13, o primeiro, por localizar-se próximo a um riacho poluído, com depósito de lixo a céu aberto e circulação de animais e o poço P13, por apresentar problemas construtivos, e com fossa séptica próxima a esse ponto. Os demais poços rasos apresentaram contaminação em pelo menos uma das campanhas. Quanto aos poços profundos (Figura 3) as comparações dos dois métodos (termotolerantes e colitag) tiveram $50 \%$ de resultados idênticas (problemas construtivos ou de localização), e 50 \% não idênticos e com contaminações em pelo menos uma das campanhas realizadas, com exceção dos poços P8 e P18, que apresentaram resultados negativos.

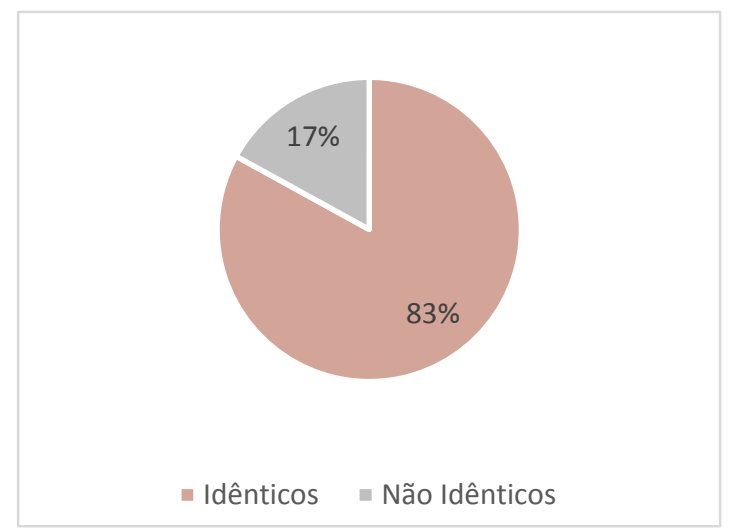

Figura 4: Comparação dos métodos para tubos múltiplos - termotolerantes e colitag - E. Coli. Em poços rasos.

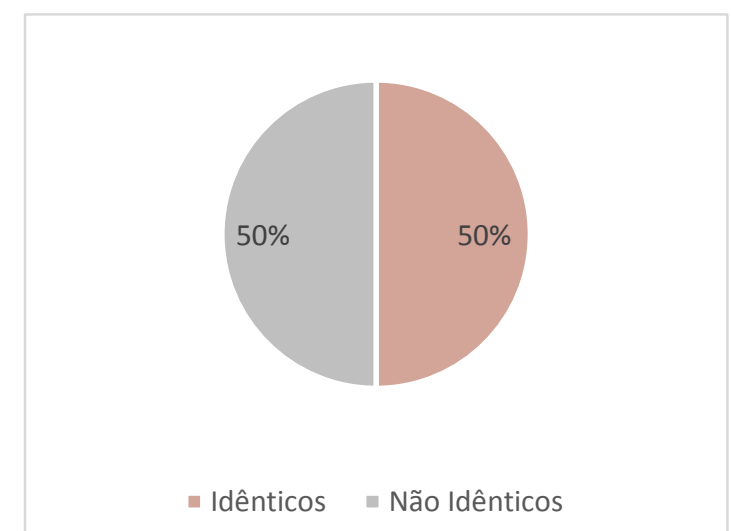

Figura 5: Comparação dos métodos para tubos múltiplos - termotolerantes e colitag - E. Coli. Em poços profundos. 
Para os exames de coliformes termotolerantes e colitag (Escherichia coli), como demostra a Figura 4, os poços rasos tiveram $83 \%$ de resultados idênticos pelos dois métodos aplicados e $17 \%$ não idênticos. Os poços P7 e P13, também apresentaram as maiores concentrações para essas bactérias, os demais poços rasos mostram-se sem contaminações, exceção o poço P16 (raso), que demostrou indícios de contaminação somente na primeira campanha. No que tange aos resultados das comparações dos resultados dos dois métodos, termotolerantes e colitag, observou-se que $50 \%$ apresentaram resultados idênticos e 50 \%, não idênticos, como mostra a Figura 5. Referente aos poços profundos, cinco deles (36\%), apresentaram contaminações por essas bactérias. Um deles, em apenas uma campanha de chuva e oito (57 \%), não apresentaram contaminações em nenhuma das campanhas para esses coliformes presentes nas fezes de humanos e animais de sangue quente. As duas metodologias trabalhadas obtiveram percentuais muito semelhantes em seus resultados, como se observa nos quatro gráficos construídos.

Na tabela 1 encontra-se a avaliação do perfil das espécies nitrogenadas (amônio e nitrato), com coletas realizadas na área urbana de Barreiras-BA.

Tabela 1- Dados de amônio e nitrato em poços rasos e profundos

\begin{tabular}{|c|c|c|c|c|c|}
\hline \multicolumn{6}{|c|}{ Concentração da série nitrogênio $\left(\mathrm{mg} \mathrm{L}^{-1}\right)$} \\
\hline \multirow{2}{*}{\multicolumn{2}{|c|}{ Poço }} & \multicolumn{2}{|c|}{$\mathrm{NH}_{4}{ }^{+}$} & \multicolumn{2}{|c|}{$\mathrm{NO}_{3}^{-}$} \\
\hline & & C1 & $\mathrm{C} 2$ & C1 & C2 \\
\hline \multirow{3}{*}{$\begin{array}{l}E \\
E \\
\stackrel{\sim}{N} \\
v\end{array}$} & P1 & 4,08 & 10,51 & 54,01 & 60,53 \\
\hline & $\mathrm{P} 2$ & 2,42 & 7,32 & 89,85 & 130,87 \\
\hline & P4 & 0,08 & 0,22 & 96,6 & 94,46 \\
\hline \multirow{3}{*}{$\begin{array}{l}\text { D } \\
\text { O. } \\
0 \\
0\end{array}$} & P7 & 2,91 & 0,03 & 26,46 & 20,76 \\
\hline & $\mathrm{P} 13$ & 5,17 & 4,28 & 100,4 & 32,8 \\
\hline & $\mathrm{P} 16$ & 0,11 & 0,08 & 41,71 & 30,0 \\
\hline \multirow{14}{*}{$\begin{array}{l}E \\
O \\
\stackrel{O}{\Lambda}\end{array}$} & P3 & 0,04 & 0,01 & 2,13 & 1,66 \\
\hline & P5 & 0,04 & 0,02 & 1,52 & 6,0 \\
\hline & P6 & 0,06 & 0,02 & 3,42 & 3,9 \\
\hline & P8 & 0,05 & 0,01 & $<\mathrm{LQ}$ & 0,38 \\
\hline & P9 & 0,1 & 0,02 & $<\mathrm{LQ}$ & 5,29 \\
\hline & P10 & 0,04 & 0,05 & $<\mathrm{LQ}$ & 7,79 \\
\hline & P11 & 0,09 & 0,01 & 4,52 & $<\mathrm{LQ}$ \\
\hline & P12 & 0,03 & 0,01 & 6,78 & 2,76 \\
\hline & P14 & 0,01 & 0,02 & 0,0 & $<\mathrm{LQ}$ \\
\hline & P15 & 0,03 & 0,01 & 8,0 & 8,5 \\
\hline & P17 & 0,01 & 0,01 & 4,20 & 0,0 \\
\hline & P18 & 0,02 & 0,02 & 4,47 & 5,27 \\
\hline & P19 & 0,1 & 0,14 & 14,43 & 2,17 \\
\hline & P20 & 0,22 & 0,06 & $<\mathrm{LQ}$ & $<\mathrm{LQ}$ \\
\hline
\end{tabular}

LQ = Limite de quantificação do método. O realce indica a inconformidade com a Resolução 
CONAMA 396/2008 e/ou a Portaria MS 2.914/2011. C1 = campanha 1; C2 = campanha 2.

Nos poços rasos P1, P2 e P13 foi detectado a presença dos íons amônio com valores superiores ao VMP para consumo humano, que é de $\left(1,5 \mathrm{mg} \mathrm{L}^{-1} \mathrm{~N}-\mathrm{NH}_{4}{ }^{+}\right)$, tanto em época de chuva quanto em estiagem, com exceção do poço P16, não sendo detectado pela técnica utilizada. . O poço P7 apresentou concentrações mais elevadas de amônio somente na (C1) de chuva, de 2,91 $\mathrm{mg} \mathrm{L}^{-1} \mathrm{~N}-\mathrm{NH}_{4}{ }^{+}$, superior ao VMP. O perfil observado para a maioria dos poços rasos indica a falta de boas condições sanitárias, podendo ser atribuído à localização e contaminação do poço em relação ao sistema de saneamento in situ (fossa) ou por infiltrações de águas servidas de lava jatos ou de limpeza de estabelecimentos comerciais, situações que independem das chuvas, além de demonstrar maior vulnerabilidade, quando comparados aos poços profundos.

Os valores de nitrito não se encontram na Tabela 1, mas pelos resultados das análises realizadas, as variações situaram-se entre 0,01 a $0,21 \mathrm{mg} \mathrm{L}^{-1} \mathrm{~N}-\mathrm{NO}_{2}{ }^{-}$, para os poços rasos e de 0,01 $0,10 \mathrm{mg} \mathrm{L}^{-1} \mathrm{~N}_{-} \mathrm{NO}_{2}^{-}$, para os poços profundos. As maiores concentrações de nitrito foram observadas nos poços rasos, com valores de 0,21 e $0,11 \mathrm{mg} \mathrm{L}^{-1} \mathrm{~N}_{-} \mathrm{NO}_{2}{ }^{-}$no poço $\mathrm{P} 13$, em época de chuva e estiagem, respectivamente, sendo um dos poços que apresentou altos índices de coliformes. Todos os resultados desse parâmetro encontraram-se abaixo do VMP $\left(1,0 \mathrm{mg} \mathrm{L}^{-1} \mathrm{~N}_{-} \mathrm{NO}_{2}{ }^{-}\right)$.

Referente ao nitrato, nos poços rasos, os valores foram de 20,76 a $130,87 \mathrm{mg} \mathrm{L}^{-1} \mathrm{~N}_{-\mathrm{NO}_{3}}^{-}$e de 0,38 a $14,43 \mathrm{mg} \mathrm{L}^{-1} \mathrm{~N}_{-} \mathrm{NO}_{3}{ }^{-}$, nos poços profundos. Dentre os compostos nitrogenados, o nitrato foi o identificado em maior quantidade acima dos padrões de potabilidade para consumo humano $\operatorname{VMP}\left(44,30 \mathrm{mg} \mathrm{L} \mathrm{L}^{-1} \cong 10,0 \mathrm{mg} \mathrm{L^{-1 }} \mathrm{N}^{-N_{3}}{ }^{-}\right)$. Em $83 \%$ dos poços rasos foram observados contaminação por nitrato acima do VMP. No caso dos poços profundos, nenhum apresentou concentrações superiores ao VMP, porém concentrações acima de 4,0 mg L ${ }^{-1} \mathrm{~N}_{-} \mathrm{NO}_{3}{ }^{-}$, já indica sinal de alerta para esta espécie, o que foi detectado em vários poços profundos nesse estudo. A presença desta espécie nos poços analisados indica que há mais contaminação antiga do que recente por matéria orgânica.

\section{5 - CONCLUSÕES}


No universo de 20 poços estudados, em 13 poços $(65 \%)$ foram observadas condições higiênicas com restrição em pelo menos uma das campanhas analisadas. As variações nos parâmetros bacteriológicos estiveram relacionadas aos aspectos construtivos dos poços, localização e sazonalidade e no que tange às comparações dos diferentes métodos, foi constatado que, no geral, os exames bacteriológicos apresentaram resultados muito semelhantes em todas as campanhas. Quanto às espécies nitrogenadas, observou-se que o íon amônio ultrapassou o VMP $\left(1,5 \mathrm{mg} \mathrm{L} \mathrm{L}^{-1} \mathrm{~N}^{-\mathrm{NH}_{4}}{ }^{+}\right)$na maior parte dos poços rasos, o nitrito encontrou-se dentro dos padrões normais e o nitrato, nos 6 poços rasos, $83 \%$ ultrapassaram o VMP $\left(10 \mathrm{mg} \mathrm{L}^{-1} \mathrm{~N}_{-\mathrm{NO}_{3}}{ }^{-}\right)$e nos 14 profundos, já se encontram valores de 4,0 a 14,43 $\mathrm{mg} \mathrm{L}^{-1} \mathrm{~N}^{-\mathrm{NO}_{3}}{ }^{-}$, que são considerados de alerta e sendo constatado também que os poços que apresentaram elevados valores de nitrato se encontram na área urbana de ocupação mais antiga da cidade.

\section{6 - REFERÊNCIAS}

ALABURDA, J.; NISHIARA, L. (1998). Presença de compostos de nitrogênio em água de poços. Revista Saúde Pública. 32, (2) pp 160-165.

AMERICAN PUBLIC HEALTH ASSOCIATION-APHA. (2005). Standard Methods for the examination of water and wasterwater. APHA/WWW/WEF Washington, $2462 \mathrm{p}$.

BARREIRAS. (2010). Plano Setorial de Abastecimento de Água e Esgotamento Sanitário de Barreiras. Prefeitura Municipal de Barreiras. 229 p.

BRASIL. (2011). Ministério da Saúde. Portaria MS no 2.914 de 12 de dezembro de 2011. Dispõe sobre os procedimentos de controle e de vigilância da qualidade da água para consumo humano e seu padrão de potabilidade. Diário Oficial [da] República Federativa do Brasil, Brasília, DF, 14 dez. 2011.

BRASIL. (2008). Resolução CONAMA n 396, de 3 de abril de 2008. Dispõe sobre a classificação e diretrizes ambientais para o enquadramento das águas subterrâneas e dá outras providências. Diário Oficial [da] República Federativa do Brasil , Brasília, DF, 7 abr. 2008.

CABRAL, N.M.T. (2007). Teores de nitrato $\left(\mathrm{NO}_{3}^{-}\right)$e amônio $\left(\mathrm{NH}_{4}{ }^{+}\right)$nas águas do aquífero Barreiras nos bairros do reduto, Nazaré e Umarizal - Belém/PA. Química Nova. 30 (8) pp. 18041808.

CONEJO, J.G.L.; COSTA, M.P.; ZOBY, J.L.G. (2007). Panorama do enquadramento dos corpos d'água no Brasil e panorama da qualidade das águas subterrâneas no Brasil. Caderno de Recursos Hídricos, 5, ANA Brasília, 124 p. 
EGYDIO SILVA, M. (1987). O sistema de dobramentos Rio Preto e suas relações com o Cráton São Francisco. 1987, 95 f. Tese ( Doutorado em Geociências)- IGC- Universidade de São Paulo, São Paulo, 1987.

FOSTER, S.; HIRATA, R.; GOMES, D.; D’ELIA, M.;PARIS, M. (2006). Proteção da qualidade da água subterrânea - um guia para empresas de abastecimento d água, órgãos municipais e agências ambientais. São Paulo: Serviços Técnicos ambientais LTDA. 101 p.

MARQUEZI, M.C.; GALLO, C.R.; DIAS, C.T.S. (2010). Comparação entre métodos para a análise de coliformes totais e E. coli em amostra de água. Rev. Instituto Adolf Lutz, 69 (3) pp. 291-296.

MEDEIROS, C.M. et al. (2009). Qualidade das águas subterrâneas na porção sedimentar da região do baixo curso do Rio Paraíba. In Anais do Simpósio Brasileiro de Recursos Hídricos, Campo Grande, MS. 18, pp. 1-15.

SANTOS, A.C. (2008). Noções de Hidroquímica. In: Feitosa, F.A.C. et al. Hidrogeologia, conceitos e aplicações. 3 ed. Rio de Janeiro: CPRM: LABHID, pp. 325-335.

SILVA, R.C.A.; ARAÚJO, T.M. (2003). Qualidade da água do manancial subterrâneo em áreas urbanas de Feira de Santana (BA). Ciência e Saúde Coletiva, 8 (4) pp. 1019-1028.

VARNIER, C.; HIRATA, R. (2002). Contaminação da água subterrânea por nitrato no parque ecológico do Tietê - São Paulo, Brasil. Revista Águas Subterrâneas, 16, pp. 97-104. 